\title{
Production of cloned horse foals using roscovitine-treated donor cells and activation with sperm extract and/or ionomycin
}

\author{
K Hinrichs ${ }^{1,2}$, Y H Choi ${ }^{1}$, D D Varner ${ }^{2}$ and D L Hartman ${ }^{3}$ \\ ${ }^{1}$ Department of Veterinary Physiology and Pharmacology, College of Veterinary Medicine and Biomedical Sciences, \\ Texas A\&M University, College Station, Texas 77843, USA, ${ }^{2}$ Department of Large Animal Clinical Sciences, College of \\ Veterinary Medicine and Biomedical Sciences, Texas A\&M University, College Station, Texas 77843, USA and \\ ${ }^{3}$ Performance Equine Associates, Whitesboro, Texas 76273, USA
}

Correspondence should be addressed to K Hinrichs; Email: khinrichs@Cvm.tamu.edu

\begin{abstract}
We evaluated the effect of different activation treatments on the production of blastocysts and foals by nuclear transfer. Donor cells were prepared using roscovitine treatment, which has previously been associated with increased production of viable offspring. All activation treatments were followed by culture in 6-dimethylaminopurine (6-DMAP) for $4 \mathrm{~h}$. In experiment 1, blastocyst production after activation by injection of sperm extract followed by treatment with ionomycin was significantly higher than that for activation with a serial treatment of ionomycin, 6-DMAP, and ionomycin $(12.5$ vs $2.8 \% ; P<0.05)$ and tended to be higher than that for injection of sperm extract alone $(3.4 \% ; P=0.07)$. In experiment 2 , there were no significant differences in blastocyst development among treatments with ionomycin once or twice, sperm extract then ionomycin, or ionomycin then sperm extract (range 4.6-7.3\%). Overall, transfer of 26 blastocysts resulted in 16 pregnancies (62\%) and 9 live foals (35\% of transferred embryos). Treatment with sperm extract followed by ionomycin produced a live foal rate per embryo transferred of $5 / 10(50 \%)$. One foal died of pneumonia $48 \mathrm{~h}$ post partum and one foal died at 1 week of age after complications during induction of anesthesia; the remaining seven foals are currently 10-14 months of age.

Reproduction (2007) 134 319-325
\end{abstract}

\section{Introduction}

Nuclear transfer (NT) has many applications in the horse for both research and clinical use; however, relatively little work has been done on NT in this species. Currently, only four viable horse foals resulting from adult somatic cell NT have been reported in the literature (Galli et al. 2003, Lagutina et al. 2005, Hinrichs et al. 2006), and three mule foals have been produced from NT using fetal cells (Woods et al. 2003, Vanderwall et al. 2004a). As in other species, the rate of pregnancy loss in the horse after transfer of NT embryos has been high in most reports (75-100\% of established pregnancies; Galli et al. 2003, Woods et al. 2003, Vanderwall et al. 2004b, Lagutina et al. 2005). However, when roscovitinetreated donor cells were used for equine NT, in conjunction with injection of sperm extract for activation, transfer of eight blastocysts resulted in birth of two viable foals (Hinrichs et al. 2006). Roscovitine treatment of donor cells was reported to significantly increase the proportion of viable calves born after NT (Gibbons et al. 2002); this treatment may work by arresting donor cells in a phase of G1 that is amenable to reprogramming by the oocyte cytoplasm.

Currently, a major barrier to the efficient production of NT horse foals is the low rate of blastocyst development from reconstructed oocytes in this species. Reported equine NT blastocyst development rates, including those from our laboratory, have ranged from 3 to $10 \%$ (Galli etal. 2003, Lagutina et al. 2005, Hinrichs et al. 2006). In contrast, equine blastocyst development after intracytoplasmic sperm injection (ICSI) of oocytes in our laboratory is typically 25-35\% (Hinrichs et al. 2005, Choi et al. 2006a, 2006b). The inefficiency of blastocyst development in NT embryos may be related to the activation methods used, as effective methods for activation have not been well established in horse oocytes.

In other species, oocyte activation treatment has been shown to affect not just initial resumption of meiosis, nuclear decondensation, and cleavage, but the success of further development to and after the blastocyst stage. The number of calcium oscillations occurring at exit from meiosis and at the first mitotic division in rabbit and mouse oocytes has been manipulated by electrical pulse (Ozil 
1990, Ozil \& Huneau 2001) or by constant or repeated exposure to strontium (Bos-Mikich et al. 1997). In these studies, a more optimal activation stimulus, i.e. a greater number of oscillations and/or oscillations of higher amplitude, resulted in significantly improved postimplantation development.

Activation methods used in NT in the horse include exposure to calcium ionophore (Galli et al. 2003, Woods et al. 2003, Lagutina et al. 2005) and injection of sperm extract (Hinrichs et al. 2006). Exposure to calcium ionophore induces one high-amplitude calcium spike in oocytes (Rinaudo et al. 1997, Tomashov-Matar et al. 2005, Jellerette et al. 2006). This may be sufficient to enable exit from meiotic arrest, via destruction of maturation promoting factor and other factors, especially if oocytes are subsequently cultured in the presence of 6-dimethylaminopurine (6-DMAP), a protein kinase inhibitor. However, one calcium spike may not provide an optimal stimulus for continued development. Injection of stallion sperm cytosolic extract into equine oocytes induced calcium oscillations at 10- to 30-min intervals, which lasted for up to 120 min after injection and were associated with activation (Bedford et al. 2003). Injection of sperm extract could potentially also be associated with calcium oscillations at the first mitosis as seen in fertilized, but not parthenogenetically activated, mouse zygotes (Kono et al. 1996). The more physiological stimulus associated with sperm extract injection may be related to the relatively high efficiency of foal production from equine NT blastocysts produced by this method (Hinrichs et al. 2006). Induction of repeated calcium oscillations may not only provide a superior activation stimulus, but also directly relate to gene expression within the transferred chromatin, as the amplitude and duration of calcium signals has been shown to control differential activation of transcriptional regulators and to stimulate gene expression in somatic cells (Dolmetsch et al. 1997, Li et al. 1998).

Since normal activation response is modulated by both calcium spike amplitude and frequency, we hypothesized that the combination of an initial large amplitude signal, as generated by ionophore exposure, followed by repeated oscillations as generated by sperm extract injection, may further increase blastocyst development and live foal rate over either technique used alone. The current study was conducted to determine the effect of activation by exposure to calcium ionophore, injection of sperm extract, or a combination of these, on blastocyst production after equine NT with roscovitine-treated donor cells, and to evaluate the rate of pregnancy and live birth after transfer of in vitro cultured NT blastocysts produced using the different activation methods.

\section{Materials and Methods}

Oocyte collection from abattoir-derived ovaries was conducted as described previously (Hinrichs \& Williams
1997). Briefly, oocytes were collected by scraping individual follicles using a $0.5 \mathrm{~cm}$ bone curette. The contents of the curette were washed into individual Petri dishes with Hepes-buffered M199 with Hanks' salts (Gibco Life Technologies Inc., Grand Island, NY, USA) plus ticarcillin $(0.1 \mathrm{mg} / \mathrm{ml}$; SmithKline Beecham Pharmaceuticals, Philadelphia, PA, USA). The contents of the Petri dishes were examined using a dissection microscope at 10-20× magnification. Oocyte-cumulus complexes were classified as compact, expanded, or degenerating depending on the expansion of both mural granulosa and cumulus (Hinrichs et al. 2002). Oocytes with any sign of expansion of either the cumulus or the mural granulosa (from having individual cells visible protruding from the surface to having full expansion with copious matrix visible between cells) led to the classification of expanded (Ex). Oocytes having both compact cumulus and compact mural granulosa were classified as compact. Only Ex oocytes were used in this study.

Recovered oocytes were held in a mixture of 40\% M199 with Earle's salts, 40\% M199 with Hanks' salts, and 20\% fetal bovine serum (FBS), in $1.1 \mathrm{ml}$ autosampler borosilicate glass vials (National Scientific Co., Duluth, GA, USA) at $22-27^{\circ} \mathrm{C}$ for $16-18 \mathrm{~h}$ to manipulate the time of onset of maturation (Choi et al. 2006a). Oocytes were then washed thrice in maturation medium (M199 with Earle's salts, $5 \mathrm{mU} / \mathrm{ml}$ follicle-stimulating hormone, 10\% FBS, and $25 \mu \mathrm{g} / \mathrm{ml}$ gentamycin sulfate) and cultured in microdroplets of maturation medium under light white mineral oil at a ratio of $10 \mu \mathrm{l}$ medium per oocyte at $38.2{ }^{\circ} \mathrm{C}$ in $5 \% \mathrm{CO}_{2}$ in air for $24 \mathrm{~h}$. After culture, oocytes were denuded of cumulus by pipetting in $0.05 \%$ hyaluronidase and those with a polar body were used for NT.

\section{Nuclear transfer}

Fibroblasts were obtained by culture of skin biopsy samples. Cells in the passages 4-7 were utilized; through these passages, cultures had been frozen and thawed 1-2 times at the time of use. Cells were treated, while actively growing, with $15 \mu \mathrm{g} / \mathrm{ml}$ R-roscovitine (Sigma) for the $24 \mathrm{~h}$ preceding NT. The cells were trypsinized before use and were washed and held in CZB-M (Choi et al. 2003) without glutamine, non-essential amino acids, or FBS, but supplemented with $2 \%$ polyvinylpyrrolidone (CZB-M/2\% PVP), for a maximum of $30 \mathrm{~min}$ before being transferred to cytoplasts.

Oocytes having a first polar body after in vitro maturation were incubated for 10-15 min in CZB-H (Choi et al. 2003) with $10 \%$ FBS containing $0.5 \mu \mathrm{g} / \mathrm{ml}$ Hoechst 33342 (Sigma) and $5 \mu \mathrm{g} / \mathrm{ml}$ cytochalasin B (Sigma). Oocytes were then held in CZB-M with a holding pipette (120-140 $\mu \mathrm{m}$ outer diameter) under an inverted microscope equipped with Eppendorf micromanipulators. The zona pellucida of the oocyte was drilled using an enucleation pipette $(10-13 \mu \mathrm{m}$ outer 
diameter) attached to a piezo drill (Prime Tech Ltd, Ibaraki, Japan), and the polar body and metaphase plate were aspirated into the enucleation pipette. After enucleation, the resulting cytoplasts were held in CZB-H with $10 \%$ FBS. The injection of fibroblast cells into the enucleated equine oocytes was performed as previously described (Hinrichs et al. 2006). Briefly, the outside diameter of the injection pipette was 8-9 $\mu \mathrm{m}$. Immediately before injection, a fibroblast cell of small to medium size (13-15 $\mu \mathrm{m}$ diameter) within the cell population (range of 11-23 $\mu \mathrm{m}$ diameter) was selected. The cell was held in CZB-M with 2\% PVP and was gently aspirated in and out of the injection pipette until the cell membrane was broken. Donor cell injection was carried out in a $100 \mu \mathrm{l}$ drop of CZB-M with $10 \%$ FBS and reconstructed oocytes were held in CZB-H.

For oocytes activated with sperm extract, reconstructed oocytes were injected with 2-4 pl (volume estimated from the length of the liquid column and the diameter of the pipette) of sperm extract, prepared as previously described (Choi et al. 2002). All oocytes were treated after activation by culture in the presence of $2 \mathrm{mM}$ 6-DMAP in CZB-H with $10 \%$ FBS for $4 \mathrm{~h}$. They were then washed and were cultured in microdroplets of DMEM/F-12 (Sigma) with 10\% FBS under oil in a humidified atmosphere of $5 \% \mathrm{O}_{2}, 5 \% \mathrm{CO}_{2}$, and $90 \%$ $\mathrm{N}_{2}$ at $38.2{ }^{\circ} \mathrm{C}$. Medium was changed on days 3 and 5 . Embryos were examined for cleavage on day 3 , and were evaluated on days 7 and 8 of culture for development to the blastocyst stage. Embryos showing organization of an outer presumptive trophoblast layer with decreasing density of inner cells were considered to be blastocysts and were prepared for transfer to recipient mares (see below). Presumptive morulae were fixed in buffered formol saline, mounted on a slide with $6.5 \mu \mathrm{l}$ of 9:1 glycerol:PBS containing $2.5 \mu \mathrm{g} / \mathrm{ml}$ Hoechst 33258, and examined using fluorescence microscopy to determine the nucleus number. Embryos were classified as morulae if they contained more than 32 cells but did not have an organized outer rim of cells, and as blastocysts if they contained more than 64 cells and had started organization of outer presumptive trophoblast cells.

For transfer to mares, blastocysts were placed in $1 \mathrm{ml}$ equilibrated DMEM/F-12 with $10 \%$ FBS in a glass vial, wrapped in $120 \mathrm{ml}$ ballast at $38.2^{\circ} \mathrm{C}$, placed in a shipping container (Equitainer, Hamilton Research Inc., South Hamilton, MA, USA) in which the coolant cans had been warmed to $38.2{ }^{\circ} \mathrm{C}$, and shipped $4-6 \mathrm{~h}$ before transfer to recipient mares. Transfer was performed transcervically (one blastocyst per mare) to recipients that had ovulated from the day of NT to 4 days afterward. In the horse, optimal synchrony is achieved when recipients ovulate from 1 day before to 3 days after donor ovulation (day 0). In vivo, the time of fertilization is on average $12 \mathrm{~h}$ before day 0 , thus it was anticipated that recipients ovulating from the day of NT to 4 days after would be in optimal synchrony. Because of recipient availability, not all blastocysts were transferred. In the rare case that there was more than one embryo available on a given day and there were fewer recipients than embryos, we transferred the embryo from the group that had fewer transfers already performed.

Pregnancies were evaluated by transrectal ultrasonography starting 5 days after transfer.

\section{Experiment 1}

Donor cells were recovered from a skin biopsy from a 25-year-old stallion. Reconstructed oocytes were subjected to one of four different activation treatments: 1 ) injection of stallion sperm extract; 2) incubation with ionomycin, $5 \mu \mathrm{M}$ in CZB-M without nonessential amino acids, glutamine or serum but supplemented with $0.02 \%$ polyvinyl alcohol, at $38{ }^{\circ} \mathrm{C}$ for $4 \mathrm{~min}$; 3 ) exposure to ionomycin as in (2), culture in $2 \mathrm{mM} 6$-DMAP in CZB-H for $2 \mathrm{~h}$ at $38.2{ }^{\circ} \mathrm{C}$ in $5 \% \mathrm{CO}_{2}$ in air and then a second ionomycin exposure $(\mathrm{I} / 6 \mathrm{D} / \mathrm{I})$; or 4$)$ sperm extract injection as in (1), incubation in CZB-H for $20 \mathrm{~min}$ at $38.2{ }^{\circ} \mathrm{C}$ in $5 \% \mathrm{CO}_{2}$ in air, followed by exposure to ionomycin as in (2) $(\mathrm{SE}+\mathrm{I})$. Oocytes in all treatments were subsequently cultured in the presence of 6-DMAP for $38.2{ }^{\circ} \mathrm{C}$ in $5 \% \mathrm{CO}_{2}$ in air for $4 \mathrm{~h}$, then placed in embryo culture as described above. Cultures were evaluated at 7 and 8 days after NT and blastocysts were shipped for transfer.

\section{Experiment 2}

Cells used were collected from skin biopsies from a 27-year-old mare (four replicates) and a 17-year-old gelding (six replicates). Reconstructed oocytes were subjected to one of four different activation treatments: 1) ionomycin treatment as for experiment $1 ; 2$ ) ionomycin treatment, followed by holding for $20 \mathrm{~min}$ in $\mathrm{CZB}-\mathrm{H}$ at $38.2{ }^{\circ} \mathrm{C}$ in $5 \% \mathrm{CO}_{2}$ in air, then a second ionomycin treatment $(2 \times \mathrm{I}) ; 3)$ injection with sperm extract, holding for $20 \mathrm{~min}$, followed by ionomycin treatment $(\mathrm{SE}+\mathrm{I}$, equivalent to treatment 4 in experiment 1); or 4) ionomycin treatment followed by holding for $20 \mathrm{~min}$, then injection with sperm extract $(I+S E)$. Oocytes in all treatments were subsequently cultured in the presence of 6-DMAP for $4 \mathrm{~h}$ before being placed in embryo culture. Cultures were evaluated at 7 and 8 days after NT and blastocysts were shipped for transfer.

\section{Statistical analysis}

Cleavage, blastocyst development, pregnancy, and live foal rates were analyzed among treatments using $\chi^{2}$ analysis, with Fisher's exact test used when a value of $<5$ was expected for any parameter. 


\section{Results}

\section{Experiment 1}

For this experiment, 249 ovaries were processed, and 1472 follicles yielded $477 \mathrm{Ex}, 233 \mathrm{Cp}$, and 65 degenerating oocytes. Nine Ex oocytes were broken during cumulus removal after maturation culture. Of the remaining 468 oocytes, 323 (69\%) were found to have polar bodies after culture. Twenty-five mature oocytes were used for another project, and 298 were used for this experiment. Of these, 281 (94\%) oocytes were successfully enucleated and 274 (92\%) successfully injected with donor cells. Seven injected oocytes were used for preliminary experiments; 251 of the remaining 267 oocytes survived activation treatment and were cultured for embryo development.

The cleavage and blastocyst formation rates for the four activation treatments are presented in Table 1. Blastocyst development was significantly higher in the $\mathrm{SE}+\mathrm{I}$ than in the $\mathrm{I} / 6 \mathrm{D} / \mathrm{I}$ treatment $(12.5$ vs $2.8 \%$ respectively; $P<0.05)$.

The outcome of embryos transferred from the different activation treatments is presented in Table 1. Overall, 13 blastocysts were transferred to recipient mares. Nine mares (69\%) established pregnancy after embryo transfer. All pregnancies appeared to progress normally through the first 45 days as assessed by transrectal ultrasonography. Two pregnancies were lost during gestation, at 6 and 10 months. The 6 -month fetus, lost at pasture, had suffered predation and most abdominal organs were missing. No additional abnormalities were noted on necropsy of either fetus, and the cause of abortion was not determined. Of the seven pregnancies that proceeded to term, one foal was delivered by Caeserian section due to contracture of the front limbs; this foal was dead at birth. On necropsy, the only additional abnormalities found in this fetus were an enlarged spleen and a congenital umbilical hernia (omphalocoele). The remaining six foals were delivered with minimal assistance between 326 and 341 days of gestation. One foal died at $48 \mathrm{~h}$ of age; the only abnormal finding on necropsy was pneumonia. The remaining five foals were viable and are currently 13-14 months of age (Fig. 1).
Typing for 13 equine microsatellites by an outside laboratory (Veterinary Genetics Laboratory, University of California at Davis) of hair bulbs from live foals or tissue obtained at necropsy from dead fetuses/foals confirmed that all nine were of the same DNA type as the donor fibroblasts.

\section{Experiment 2}

For this experiment, 289 ovaries were processed, and 1809 follicles yielded $635 \mathrm{Ex}, 275 \mathrm{Cp}$, and 80 degenerating oocytes. Eighteen Ex oocytes were broken during cumulus removal after maturation culture. Of the remaining 617 oocytes, 400 (65\%) were found to have polar bodies after culture. Of these, $367(92 \%)$ oocytes were successfully enucleated, and 355 (89\%) were successfully injected with donor cells; 338 oocytes survived activation treatment and were cultured for embryo development.

The cleavage and blastocyst formation rates for the four activation treatments are given in Table 2. There were no significant differences in cleavage or blastocyst formation rates among treatments.

The outcome of embryos transferred from the different activation treatments is presented in Table 2. Thirteen blastocysts were transferred to recipient mares, and seven pregnancies were established (54\%). One pregnant recipient mare was euthanized after exhibiting neurologic signs; necropsy was performed but the cause was not determined. Of the remaining six pregnant recipients, two lost the pregnancy before day 30 and one lost the pregnancy at 7 months gestation. The only abnormality identified on necropsy of the 7-month fetus was a congenital umbilical hernia. The remaining three recipient mares delivered live foals at 343,349 , and 352 days of gestation. The foal born at 352 days of gestation underwent anesthesia for exploration of a possible bladder tear at 4 days of age; this foal suffered a prolonged period of low blood pressure during anesthetic induction, became comatose and died 3 days later. Necropsy showed no tear in the bladder and extensive cerebral edema attributed to hypoxemia. The remaining foals are currently 12 and 10 months of age.

Typing for 13 equine microsatellites by an outside laboratory (Veterinary Genetics Laboratory, University of California at Davis) of hair bulbs from the three foals born live and tissue obtained at necropsy of the fetus

Table 1 Cleavage, blastocyst development, and pregnancy outcome for embryos produced using the different activation treatments (experiment 1 ).

\begin{tabular}{|c|c|c|c|c|c|c|}
\hline $\begin{array}{l}\text { Activation } \\
\text { treatment }^{\mathrm{a}}\end{array}$ & No. cultured & Cleavage (\%) & Blastocysts (\%) & Embryos transferred & Pregnancies & Live foals \\
\hline Sperm extract & 59 & $40(68)$ & $2(3.4)^{*, t}$ & 2 & $2(100 \%)^{b}$ & 0 \\
\hline lonomycin & 65 & $52(80)$ & $5(7.7)^{*,+}$ & 5 & $2(40 \%)$ & 2 \\
\hline $1 / 6 \mathrm{D} / \mathrm{l}$ & 71 & $53(75)$ & $2(2.8)^{*}$ & 1 & $1(100 \%)^{\mathrm{c}}$ & 0 \\
\hline$S E+I$ & 56 & $52(93)$ & $7(12.5)^{\dagger}$ & 5 & $4(80 \%)$ & $4^{\mathrm{d}}$ \\
\hline
\end{tabular}

${ }^{*}{ }^{\dagger}$ Within columns, values with different superscripts are significantly different.

${ }^{\mathrm{a}}$ All activation treatments were followed by incubation in 6-DMAP. ${ }^{\mathrm{b}}$ One pregnancy was lost at 10 months; one foal was stillborn at term. ${ }^{\mathrm{c}}$ This pregnancy was lost at 6 months gestation. ${ }^{\mathrm{d}}$ One foal died of pneumonia $48 \mathrm{~h}$ post partum. 


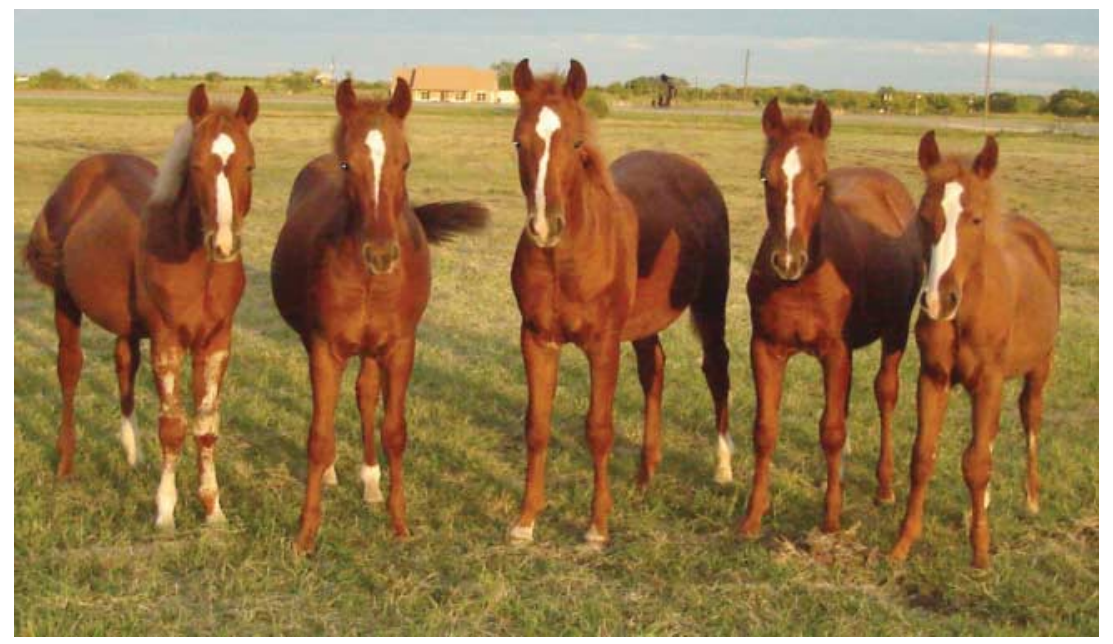

Figure 1 Five foals produced by nuclear transfer from a single donor cell line.

aborted at 7 months pregnancy confirmed that the fetuses/foals were of the same DNA type as their respective donor fibroblasts.

\section{Discussion}

The results of this study show that activation treatment significantly affects blastocyst production in horse NT embryos; in experiment 1 , oocytes activated by injection of sperm extract followed by ionomycin treatment had a significantly higher rate of blastocyst development than did those treated with ionomycin, 6-DMAP, then a second ionomycin treatment $2 \mathrm{~h}$ later $(\mathrm{I} / 6 \mathrm{D} / \mathrm{l})$, and tended $(P=0.07)$ to have a higher blastocyst development than did oocytes injected with sperm extract alone (the treatment used to produce the two cloned foals in our previous report (Hinrichs et al. 2006)). In experiment 1 , the second ionomycin treatment was performed $2 \mathrm{~h}$ after the first to provide two large amplitude calcium spikes within the normal period in which calcium oscillates in the horse oocyte after injection of sperm (120 min; Bedford et al. 2003). Ionomycin treatment in the $\mathrm{SE}+\mathrm{I}$ group was performed 20 min after sperm extract injection to provide a large amplitude spike at the typical interval of oscillation after sperm extract injection (10-30 min; Bedford et al. 2003, 2004). In experiment 2, the effect of ionomycin treatment before or after sperm extract injection was evaluated to determine the effect of the timing of the calcium spike in relation to oscillations induced by sperm extract injection; the time between the two ionomycin treatments in the $2 \times 1$ group was changed to $20 \mathrm{~min}$ to duplicate the timing between ionomycin and sperm extract injections in the other treatments in this experiment.

While not statistically different from other treatments, the $\mathrm{SE}+\mathrm{I}$ provided the highest blastocyst development rate in both experiments (12.5 and $7.3 \%)$. The $1 \times$ ionomycin and $\mathrm{SE}+\mathrm{I}$ treatments were performed in both experiments. Treatment with SE+I was associated with a relatively high pregnancy rate per embryo transferred (7/10), and a high live foaling rate per pregnancy (5/6; one pregnant recipient having been euthanized), for an overall live foal per embryo transferred of 5/10, which would appear to support the hypothesis that improved calcium oscillation activity at activation supports embryo viability. However, the $1 \times$ ionomycin treatment also yielded acceptable pregnancy and live foal rates (3/8 and $2 / 3$ respectively). The rate of production of live foals per embryo transferred achieved with $1 \times$ ionomycin treatment $(2 / 8,25 \%)$ is higher than that reported in other laboratories using a one-time ionomycin treatment for equine NT with adult somatic cells, followed by either cycloheximide (0/62, Vanderwall et al. 2004b) or cycloheximide plus 6-DMAP $(1 / 17,6 \%$, Galli et al. 2003; 1/101, 1\%, Lagutina et al. 2005). The reason for

Table 2 Cleavage, blastocyst development, and pregnancy outcome for embryos produced using the different activation treatments (experiment 2).

\begin{tabular}{|c|c|c|c|c|c|c|}
\hline $\begin{array}{l}\text { Activation } \\
\text { treatment }^{\mathrm{a}}\end{array}$ & No. cultured & Cleavage $(\%)$ & Blastocysts (\%) & Embryos transferred & Pregnancies & Live foals \\
\hline lonomycin & 86 & $67(78)$ & $5(5.8)$ & 3 & $1(33 \%)^{b}$ & 0 \\
\hline $2 \times 1$ & 87 & $68(78)$ & $4(4.6)$ & 3 & $2(66 \%)^{\mathrm{c}}$ & 1 \\
\hline $\mathrm{I}+\mathrm{SE}$ & 83 & 77 (93) & $4(4.8)$ & 2 & $1(50 \%)$ & 1 \\
\hline$S E+I$ & 82 & 71 (87) & $6(7.3)$ & 5 & $3(60 \%)^{d}$ & $1^{\mathrm{e}}$ \\
\hline
\end{tabular}

${ }^{\mathrm{a}}$ All activation treatments were followed by incubation in 6-DMAP. ${ }^{\mathrm{b}}$ This pregnancy was lost at 7 months. ${ }^{\mathrm{c}}$ One pregnancy was lost at day $30 .{ }^{\mathrm{d}}$ One pregnancy was lost at day 30; one pregnant recipient was euthanized due to neurologic disease. ${ }^{\mathrm{e}}$ This foal died after complications during anesthesia to explore a suspected bladder tear. 
the greater live foal production efficiency of $1 \times$ ionomycin treatment in the current study is not clear, as multiple variables exist between the procedure used in this study and that used by other laboratories, including method of donor cell preparation, method of oocyte reconstruction, treatment following ionophore exposure, and embryo culture techniques.

Roscovitine-treated donor cells were associated with relatively efficient equine cloning in a previous study (Hinrichs et al. 2006). In that study, we attempted to assess embryo development and pregnancy rates using donor cells grown to confluence versus those treated with roscovitine, but too few embryos developed in the confluent group to make a meaningful comparison. However, it is notable that in both equine studies in which roscovitine was used, few of the pregnancies produced from roscovitine-treated cells were lost in early gestation (0/3, Hinrichs et al. 2006; 2/16, this study) regardless of activation treatment; this is in contrast to previous reports on equine NT using donor cells prepared by serum starvation, growth to confluence, or no treatment (cumulus cells in $\geq 3$ day culture) in which $11 / 14$, $7 / 7,2 / 4$, and 10/19 pregnancies were lost before 90 days (Galli et al. 2003, Woods et al. 2003, Vanderwall et al. 2004b, Lagutina et al. 2005). Roscovitine treatment of donor cells in cattle NT was associated with survival of seven calves from six pregnancies, as opposed to one calf from five pregnancies for serum-deprived cells (Gibbons et al. 2002). These authors found that roscovitine was more effective in synchronizing cells in G0/G1 than was serum deprivation. In contrast, we found that proportions of cells in G0/G1 were not significantly different between roscovitine-treated and serum-deprived cells (Hinrichs et al. 2006). This was true over all cells as well as when selection for small cell size, as is done during NT, was taken into account. It is possible that the increased efficiency associated with roscovitine treatment of donor cells is due to the phase of G1 in which cells are arrested (i.e. early G1; Keezer \& Gilbert 2002), as a similar increase in viable offspring was noted when donor cells were utilized immediately after cytokinesis (also in early G1; Kasinathan et al. 2001).

While blastocyst development of equine NT embryos was higher in this study than in our previous report (Hinrichs et al. 2006), it continues to be inferior to that for those of other species, and for ICSI embryos within our laboratory. Blastocyst development in the equine embryo proceeds differently from that in the mouse or bovine embryo; after the outer embryonic cells differentiate to form the trophoblast, a network of inner cells appears to go on to form both the inner cell mass and to initiate the endodermal lining of the trophoblast (Enders et al. 1993). The low rate of in vitro blastocyst development of equine NT embryos, when considered with the high pregnancy rate and rate of live births seen from these blastocysts after transfer, suggests that some selection for adequate reprogramming may be occurring in these embryos during the first 8 days of development in vitro.
The results of this study show that production of cloned foals by transfer of embryos produced using roscovitine-treated donor cells and activated by treatment with ionomycin and sperm extract may be efficient enough for this technique to be utilized for clinical or research purposes. Further work is needed to assess the relationship of roscovitine treatment of donor cells to subsequent fetal health, and to explore gene function during blastocyst development in this species.

\section{Acknowledgements}

This work was supported by the Link Equine Research Endowment Fund, Texas A\&M University; Cryozootech S A; and the Smart Little Lena Co-Managers. The authors declare that there is no conflict of interest that would prejudice the impartiality of this scientific work.

\section{References}

Bedford SJ, Kurokawa M, Hinrichs K \& Fissore RA 2003 Intracellular calcium oscillations and activation in horse oocytes injected with stallion sperm extracts or spermatozoa. Reproduction 126 489-499.

Bedford SJ, Kurokawa M, Hinrichs K \& Fissore RA 2004 Patterns of intracellular calcium oscillations in horse oocytes fertilized by intracytoplasmic sperm injection: possible explanations for the low success of this assisted reproduction technique in the horse. Biology of Reproduction 70 936-944.

Bos-Mikich A, Whittingham DG \& Jones KT 1997 Meiotic and mitotic $\mathrm{Ca}^{2+}$ oscillations affect cell composition in resulting blastocysts. Developmental Biology 182 172-179.

Choi YH, Love CC, Chung YG, Varner DD, Westhusin ME, Burghardt RC \& Hinrichs K 2002 Production of nuclear transfer horse embryos by piezo-driven injection of somatic cell nuclei and activation with stallion sperm cytosolic extract. Biology of Reproduction 67 561-567.

Choi YH, Chung YG, Walker SC, Westhusin ME \& Hinrichs K 2003 In vitro development of equine nuclear transfer embryos: effects of oocyte maturation media and amino acid composition during embryo culture. Zygote 11 77-86.

Choi YH, Love LB, Varner DD \& Hinrichs K 2006a Holding immature equine oocytes in the absence of meiotic inhibitors: effect on germinal vesicle chromatin and blastocyst development after intracytoplasmic sperm injection. Theriogenology 66 955-963.

Choi YH, Love LB, Varner DD \& Hinrichs K 2006b Blastocyst development in equine oocytes with low meiotic competence after suppression of meiosis with roscovitine prior to in vitro maturation. Zygote 14 1-8.

Dolmetsch RE, Lewis RS, Goodnow CC \& Healy JI 1997 Differential activation of transcription factors induced by $\mathrm{Ca}^{2+}$ response amplitude and duration. Nature 386 855-858.

Enders AC, Schlafke S, Lantz KC \& Liu IKM 1993 Endoderm cells of the equine yolk sac from day 7 until formation of the definitive yolk sac placenta. Equine Veterinary Journal Supplement 15 3-9.

Galli C, Lagutina I, Crotti G, Colleoni S, Turini P, Ponderato N, Duchi R \& Lazzari G 2003 A cloned horse born to its dam twin. Nature 424635.

Gibbons J, Arat S, Rzucidlo J, Miyoshi K, Waltenburg R, Respess D, Venable A \& Stice S 2002 Enhanced survivability of cloned calves derived from roscovitine-treated adult somatic cells. Biology of Reproduction 66 895-900. 
Hinrichs K \& Williams KA 1997 Relationships among oocyte-cumulus morphology, follicular atresia, initial chromatin configuration, and oocyte meiotic competence in the horse. Biology of Reproduction 57 377-384.

Hinrichs K, Love CC, Choi YH, Varner DD, Wiggins CN \& Reinoehl C 2002 Suppression of meiosis by inhibitors of $m$-phase proteins in horse oocytes with low meiotic competence. Zygote 10 37-45.

Hinrichs K, Choi YH, Love LB, Varner DD, Love CC \& Walckenaer BE 2005 Chromatin configuration within the germinal vesicle of horse oocytes: changes post mortem and relationship to meiotic and developmental competence. Biology of Reproduction $\mathbf{7 2}$ 1142-1150.

Hinrichs K, Choi YH, Love CC, Chung YG \& Varner DD 2006 Production of horse foals via direct injection of roscovitine-treated donor cells and activation by injection of sperm extract. Reproduction 131 1063-1072.

Jellerette T, Melican D, Butler R, Nims S, Ziomek C, Fissore R \& Gavin W 2006 Characterization of calcium oscillation patterns in caprine oocytes induced by IVF or an activation technique used in nuclear transfer. Theriogenology 65 1575-1586.

Kasinathan P, Knott JG, Wang Z, Jerry DJ \& Robl JM 2001 Production of calves from G1 fibroblasts. Nature Biotechnology 19 1176-1178.

Keezer SM \& Gilbert DM 2002 Sensitivity of the origin decision point to specific inhibitors of cellular signaling and metabolism. Experimental Cell Research 273 54-64.

Kono T, Jones KT, Bos-Mikich A, Whittingham DG \& Carroll J 1996 A cell cycle-associated change in $\mathrm{Ca}^{2+}$ releasing activity leads to the generation of $\mathrm{Ca}^{2+}$ transients in mouse embryos during the first mitotic division. Journal of Cellular Biology 132 915-923.

Lagutina I, Lazzari G, Duchi R, Colleoni S, Ponderato N, Turini P, Crotti G \& Galli C 2005 Somatic cell nuclear transfer in horses: effect of oocyte morphology, embryo reconstruction method and donor cell type. Reproduction 130 559-567.
Li W, Llopis J, Whitney M, Zlokarnik G \& Tsien RY 1998 Cell-permeant caged InsP3 ester shows that $\mathrm{Ca}^{2+}$ spike frequency can optimize gene expression. Nature $392936-941$.

Ozil JP 1990 The parthenogenetic development of rabbit oocytes after repetitive pulsatile electrical stimulation. Development 109 117-127.

Ozil JP \& Huneau D 2001 Activation of rabbit oocytes: the impact of the $\mathrm{Ca}^{2+}$ signal regime on development. Development 128 917-928.

Rinaudo P, Pepperell JR, Buradgunta S, Massobrio M \& Keefe DL 1997 Dissociation between intracellular calcium elevation and development of human oocytes treated with calcium ionophore. Fertility and Sterility 68 1086-1092.

Tomashov-Matar R, Tchetchik D, Eldar A, Kaplan-Kraicer R, Oron Y \& Shalgi R 2005 Strontium-induced rat egg activation. Reproduction 130 467-474.

Vanderwall DK, Woods GL, Aston KI, Bunch TD, Li G-P, Meerdo LN \& White KL 2004a Cloned horse pregnancies produced using adult cumulus cells. Reproduction, Fertility and Development $\mathbf{1 6}$ 675-679.

Vanderwall DK, Woods GL, Sellon DC, Tester DF, Schlafer DH \& White KL 2004b Present status of equine cloning and clinical characterization of embryonic, fetal, and neonatal development of three cloned mules. Journal of American Veterinary Medical Association 225 1694-1699.

Woods GL, White KL, Vanderwall DK, Li G-P, Aston KI, Bunch TD, Meerdo LN \& Pate BJ 2003 A mule cloned from fetal cells by nuclear transfer. Science 3011063.

Received 9 February 2007

First decision 15 March 2007

Revised manuscript received 6 April 2007

Accepted 23 April 2007 